\title{
Assessment of Healing in Calvarial Bone Defect by Allogenic Demineralized Bone Matrix and Adipose Derived Stem Cells
}

\author{
MOHAMED S. BADAWY, M.Sc.*; SAAD S. EL-FAYOMY, M.D.*; BASIM M. ZAKI, M.D.*; \\ ABDEL-RAHMAN M. SAYED, M.D.* and FATMA A. ABUZAHRA, Ph.D.**
}

The Departments of Plastic, Burn \& Maxillofacial Surgery* and Medical Research Center**, Faculty of Medicine, Ain Shams University, Cairo, Egypt

\begin{abstract}
Background: The critical size calvarial bone defect is a challenging problem in the craniomaxillofacial field. Till now, the golden standard for its reconstruction is the autografts which harbors multiple drawbacks as availability and morbidity. So, the use of Allogenic Adipose Derived Stem Cells seeded on Demineralized bone matrix (DBM) scaffolds offer an already made new tissue regenerate that can be stored in bone banks and used when needed.
\end{abstract}

Material and Methods: 32 adult male albino rats with surgically created Calvarial bone defect $(8 \mathrm{~mm})$ in the Rt. Parietal bones were divided into 4 groups; group I, control; group 2; reconstructed by DBM; group III; ADSC seeded on DBM and group IV; ADSCs seeded on prolene mesh. Evaluated 8 weeks post-operative by Gross Evaluation Score (proposed in this study), 3D CT scans with objective analysis by a software (ImageJ $1.47 \mathrm{v}$ ) and histologically.

Results: Bone healing is evident 8 weeks post implantation with bone formation $75-100 \%$ in $62.5 \%$ of the defects that is reconstructed by ADSCs and DBM.

Conclusion: This study presents a beneficial method for reconstruction of critical size calvarial bone defects by an already made non-immunogenic new tissue regenerate.

Key Words: ADSCs -DBM-Allogenic - Stem cells - Critical size defect-Calvarial-bone healing.

\section{INTRODUCTION}

The Craniomaxillofacial surgeons are facing frequently critical sized calvarial bone defects that present a challenge for reconstruction [1]. It can result secondary to congenital or acquired causes like; infection, trauma, post tumor excision or deforming skeletal diseases [2].

Multiple treatment options are available to solve this problem. It can vary from bone grafts, bone substitutes or bone transport methods [2]. But till now the golden standard is the autograft. They offer minimum immunological rejection, complete histocompatibility and can provide the best osteoinductive, osteoconductive and osteogenic prop- erties [3]. The limitations in using autografts are the limited graft availability, bone resorption and the need for an additional surgery with resulting donor site morbidity [4].

Bone allograft is another option. It is obtained from a cadaver of the same species. It has osteoinductive ability by releasing bone morphogenic proteins (BMPs). It has also osteoconductive properties but lacks the osteogenic properties due to the absence of viable cells [5]. Despite its wide availability in various shapes and sizes without sacrificing host structures and extra donor morbidity. It fails to meet the reconstruction needs due to the difficult preservation and possible infection transmission [6,7].

A further step forward in bone reconstruction was the bone tissue engineering (BTE). Tissue engineering is to restore damaged or degenerated tissues with a functional living construct from cell development [8]. It is a new field in the bone reconstruction armamentarium that builds up a new thinking for bone replacement without extraneed for the traditional bone grafting surgeries with its complications [9].

Basically, a triad of stem cells, scaffold and growth factors should interact to regenerate a new bone reconstruct $[\mathbf{9 , 1 0}]$. Multiple studies in this field were greatly described to synthetize a novel tissue engineered bone with multiple designs by seeding diverse types of stem cells on different scaffolds.

\section{PATIENTS AND METHODS}

This study was done between October 2014 and December 2017. It was conducted at The Medical Research Center associated with Ain Shams' Faculty of Medicine and approved from 
the Research Ethics Committee (REC) of Faculty of Medicine, Ain Shams University (No: FMASU 1969/2014).

A total of 42 Male albino rats were used after approval of CARE (Committee on Animal Research and Ethics), Ain Shams University, Faculty of Medicine. It was divided into two models: Model 1: (Donor rats for adipose derived stem cells); 10 rats of young (5-6 weeks) male albino rats were used. Model 2: 32 adult (6-7 months) male albino rats weighing 260-340 grams were divided into four groups; Group I ( $\mathrm{n}=8)$ : Control group where the surgically created calvarial bone defect will be left without repair; Group II ( $\mathrm{n}=8)$ : Reconstructed by allogenic DBM without cell seeding; Group III $(n=8)$ : Allogenic DBM seeded by ASCs; Group IV $(n=8)$ : Reconstructed by prolene mesh seeded by ASCs.

\section{- Preparation of prolene mesh Scaffold:}

A prolene mesh sized $30 \times 30 \mathrm{~cm}$ was cut into small, symmetrical, circular Segments (scaffolds) of $8 \mathrm{~mm}$ diameter by using $8 \mathrm{~mm}$ biopsy punch (Fig. 1). Each segment was separately sterilized and stored.

\section{- Preparation of DBM Scaffold:}

Rats were anaesthetized using intramuscular injection of ketamine (1-2 mg/kg) which was maintained as required. Under sterile conditions, the surgical incision site (Right parietal area) was shaved with razor and lubricant then scrubbed by povidone iodine and $70 \%$ alcohol and the rat was draped by a disposable waterproof drape. A $2 \mathrm{~cm}$ incision was made along the sagittal suture, the skin; musculature and periosteum were dissected to expose the Right parietal bone. A circular defect measuring $8 \mathrm{~mm}$ diameter was then made using the $8 \mathrm{~mm}$ biopsy punch with care to avoid injury to the dura matter. The bone harvested from Group I (control) and Group IV (reconstructed by prolene mesh and ADSCs) were demineralized and used as a donor for Group II (reconstructed by DBM without cell seeding) and III (reconstructed by DBM with cell seeding) respectively. Demineralization was done by immediate bone transfer into a solution of $(0.6 \mathrm{~N} \mathrm{HCL})$ for 72 hours at $4^{\circ} \mathrm{c}$. The HCL was changed every 24 hours. The acid was then removed by washing the bone segments with distilled water for 8 hours with continuous stirring [23]. Each segment will be separately stored in small plastic tubes at minus $70^{\circ} \mathrm{c}$ while still immersed in alcohol (Fig. 2).

In this study, an $8 \mathrm{~mm}$ biopsy punch is preferred than trephine burr due to many reasons. It is easier, accurate, disposable and less expensive especially when compared with the trephine burr. It also preserves the extracted bone as a block that can be demineralized and reused as a scaffold with the same defect dimension so, no need for hardware fixation.

\section{- Harvesting inguinal pad of fat:}

Two bilateral inguinal folds Incisions were done. The inguinal bad of fat were carefully dissected, isolated and immediately transferred to a sterile petri dish. The wounds are closed with a 4.0 absorbable suture (vicryl) (Fig. 3).

\section{- Tissue processing:}

The harvested fat was washed with phosphate buffered saline (PBS) and cut into pieces of approximately $1-2 \mathrm{~mm}$ diameter inside a laminar flow. The tissue will then be rinsed three times in PBS for 5 minutes.

\section{Isolation of ADSCs:}

The minced fat was digested by adding a $0.2 \%$ collagenase type I and vigorous constant shaking in a water bath shaker for 40 minutes at $37^{\circ} \mathrm{C}$. The collagenase effect is neutralized by equal volume of complete culture medium (CCM). The CCM is reconstructed by adding $500 \mathrm{~mL}$ DMEM, $65 \mathrm{~mL}$ FBS (final conc. 13\%), and $1.5 \%$ antibiotic and anti-mycotic mixture Penicillin G (10,000 units $/ \mathrm{mL})$, streptomycin sulfate $(10,000 \mu \mathrm{g} / \mathrm{mL})$ and Amphotericin B $(25 \mathrm{mcg} / \mathrm{mL})$ in a solution of $0.85 \%$ $\mathrm{NaCL}$ (modified by medical research center team instead of $10 \%$ FBS \& $1 \%$ antibiotic/antimycotic as described by Lu et al., 2008) [24]. CCM is filtered through $0.22 \mu \mathrm{m}$ sterile filter unit then divided into aliquots and stored at $4^{\circ} \mathrm{C}$. Before the experiment, the aliquots were warmed to $37^{\circ} \mathrm{C}$. The cell suspension was centrifuged. The formed cell pellet was re-suspended in a $10 \mathrm{ml}$ of CCM to lyse the red blood cells.

\section{Culture:}

Cell pellet will be cultured in a culture flask $25 \mathrm{~cm}^{2}$ with $\mathrm{CCM}$ in the $\mathrm{CO} 2$ Incubator at $37^{\circ} \mathrm{c}$, $5 \% \mathrm{CO} 2$ and $100 \% \mathrm{RH}$. The medium was replaced every 72 hours. The non-adherent cells were discarded, and the adherent cells were washed by PBS.

\section{Expansion:}

The cell expansion was followed by the inverted microscope. The cells were harvested at 80 to $90 \%$ confluence at the $12^{\text {th }}$ day from passage zero (Fig. $4)$. 
The cultured cells were detached from the culture flasks with $0.25 \%$ trypsin-EDTA and microscrubber.

\section{- In vivo implantation:}

The scaffolds (DBM and prolene mesh) wet by DMEM solution were seeded by a $3 \times 10^{6}$ cells. Group III with surgically created calvarial bone defect was repaired by allogenic DBM with cell seeding. The dimensions of the defect and the DBM are equal so, press fit is enough for fixation. Group IV was reconstructed by prolene mesh seeded with ADSCs (Fig. 5).

Postoperatively, Analgesics and antibiotics were administered. Wounds were followed daily for signs of inflammation, disruption, hemorrhage and exudation. Euthanasia was done 8 weeks post implantation.

\section{- Biopsy harvest:}

The biopsies were taken as blocks containing the reconstructed defect and a rim of the surrounding calvarium.

\section{- Evaluation:}

In this study, 3-objectively based analytical steps was used to evaluate the results; Gross evaluation at autopsy, Radiological assessment by 3D CT scans with software analysis for the surface area of the newly formed bone (Image J $1.47 \mathrm{v}$, National Institute of Health, USA) and histological evaluation.

\section{Gross evaluation at autopsy:}

The reconstructed defects were exposed and examined. there no universal guidelines for data analysis in a well settled rating scale. So, in this current work, a proposal for a scoring system for gross evaluation of healing at autopsy is offered. It includes the four main parameters which is subdivided into multiple rating points covering the entire range or shades of healing possibility in a numerical scale in which the minimum is 4 ; indicates the worst healing and the maximum is 11 ; the best. This score was extremely helpful in this study (Table 1).

Table (1): Gross evaluation score for evaluation of bone healing at autopsy.

Gross evaluation score at autopsy

Palpation:
No healing
Soft healing
Hard healing
Transillumination:
Trans-illuminant
Non-trans-illuminant
Mobility with pressure:
Mobile
Minimal mobility
No mobility
Integration with the surrounding bone:
Absent
Incomplete
Complete
Score: ( /11) Minimum 4

\section{Radiological Evaluation:}

A 3D reconstructed CT Scanning was performed for the heads of all study groups immediately after euthanasia using a CT scanner (SOMATOM ${ }^{\circledR}$ Definition Flash 128 Dual source, Siemens Medical Solutions, Germany). The relation between the surface area of the newly formed bone to the surface area of the surgically created defect was analyzed using a software (Image J $1.47 \mathrm{v}$, National Institute of Health, USA) (Fig. 6).

\section{Histological evaluation:}

The specimens were fixed in $10 \%$ formaldehyde for 2 days, decalcified in 25\% $\mathrm{H} 2 \mathrm{SO} 4$ for 10 days and mounted in paraffin. Serial sections $5 \mu \mathrm{m}$-thick were cut by a microtome in the sagittal plane and including the defect and rim of the surrounding calvarium then stained with hematoxylin and eosin and examined by light microscopy to evaluate the qualitative bone healing.

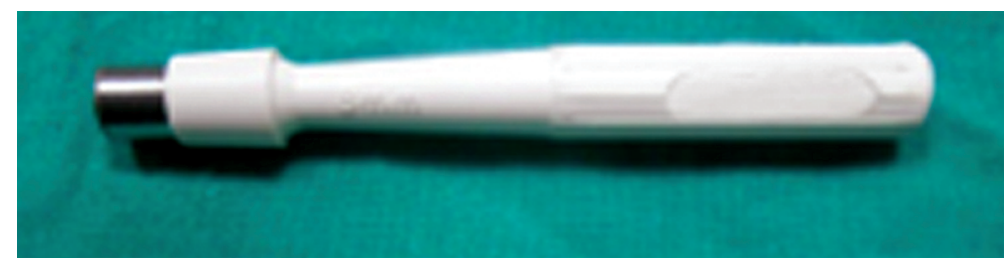

Fig. (1): The preparation of prolene mesh; Prolene mesh was cut by punch into multiple small pieces (scaffolds). 


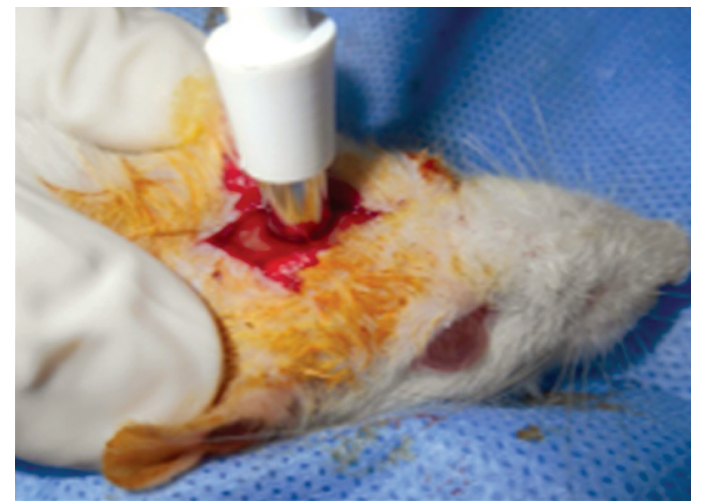

(A)

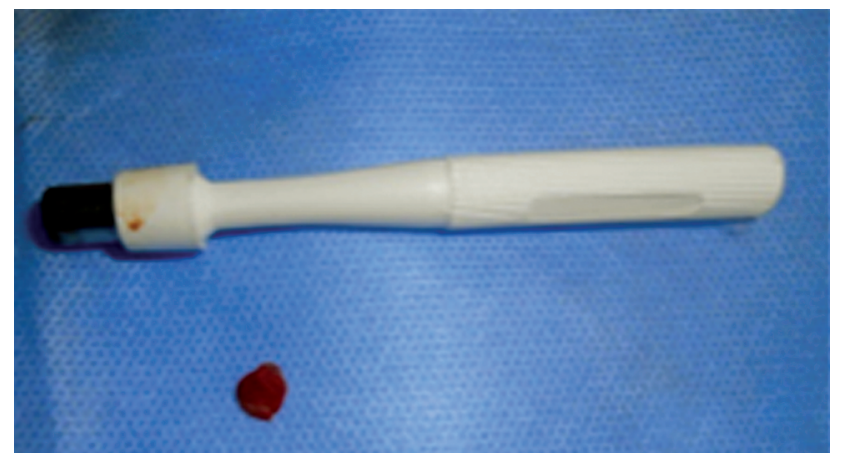

(C)

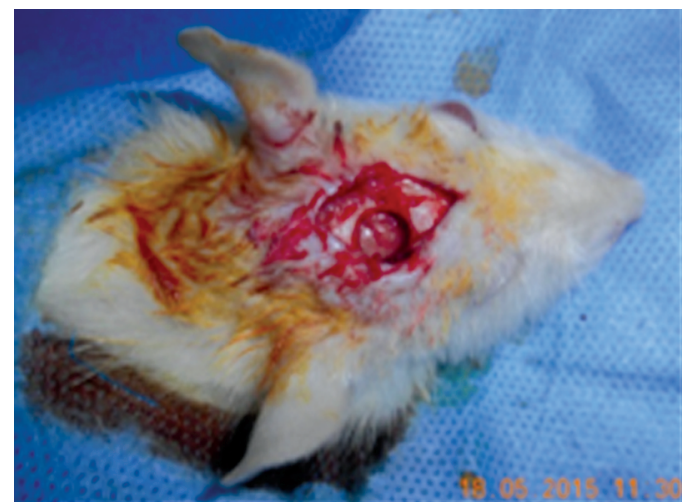

(B)

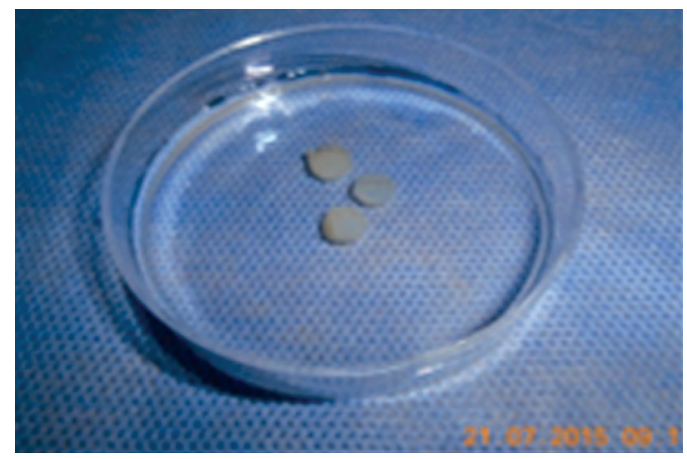

(D)

Fig. (2): Harvest of an $8 \mathrm{~mm}$ circular bone from rats calvaria; (a) Circular bone excised by $8 \mathrm{~mm}$ biopsy punch. (b) Dura intact after bone harvest. (c) Harvested bone. (d) The Demineralized bone scaffolds are immersed in alcohol.

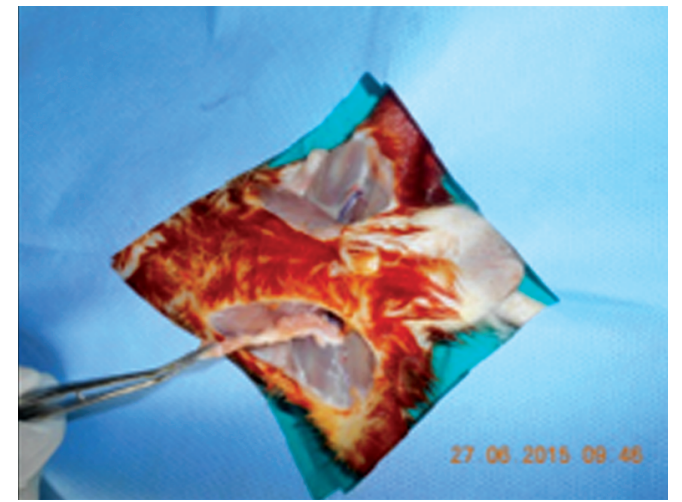

(A)

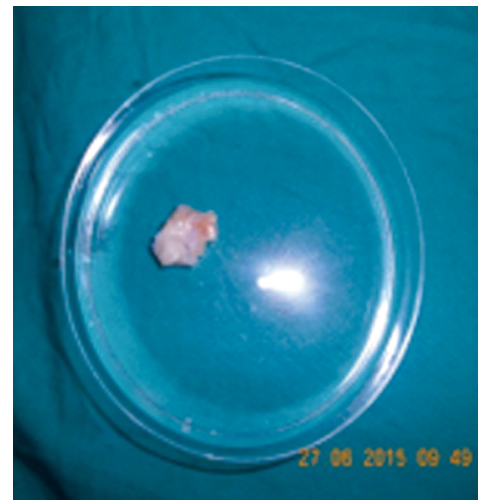

(B)

Fig. (3): Harvest of inguinal pad of fat: (a) Both inguinal folds are incised and dissected with isolation of the inguinal pad of fat. (b) The harvested inguinal pad of fat collected in a petri dish.

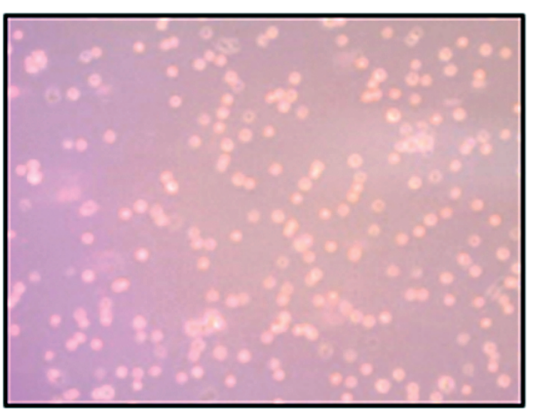

(A)

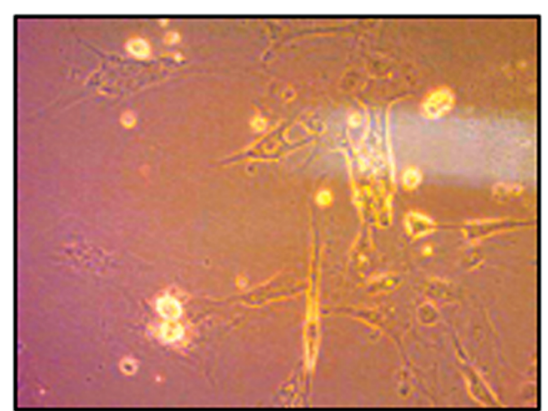

(B)

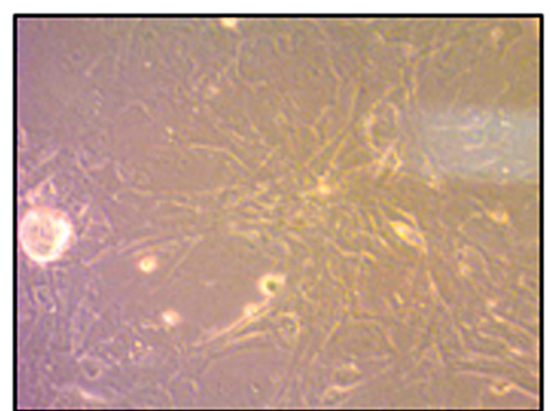

(C)

Fig. (4): Cell Expansion (X100) under inverted microscope; (a) Passage zero; the cells appearance under the inverted microscope (b) Day 3: The cells appeared as spindle shaped cells (c) Day 5: The cells are more confluent. 


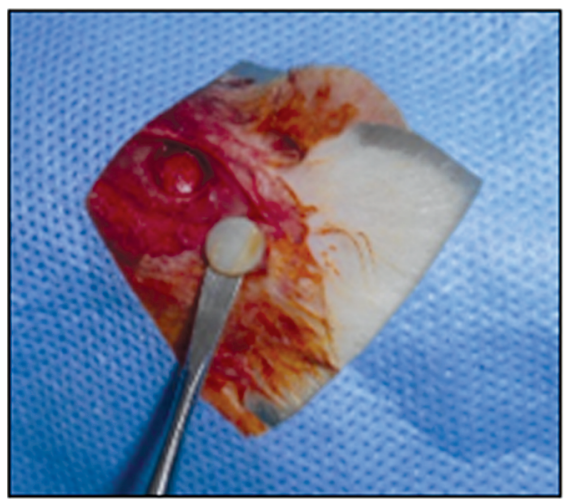

(A)

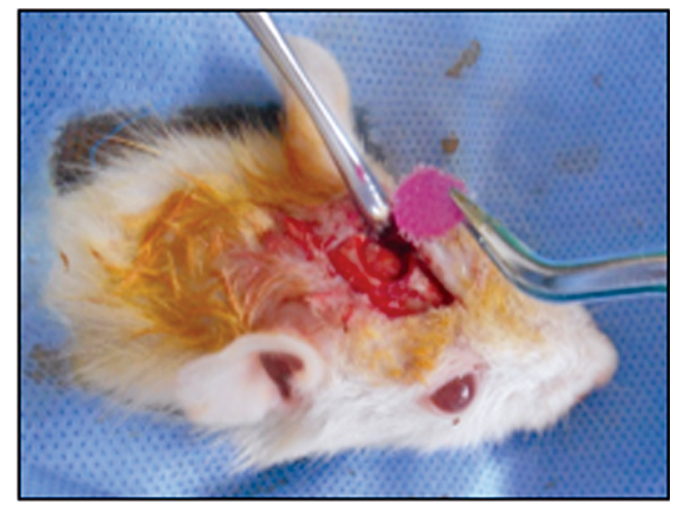

(B)

Fig. (5): In vivo implantation; (a) Group III: Allogenic DBM seeded with ASCs; (b) Group IV: Prolene mesh seeded with ADSCs.

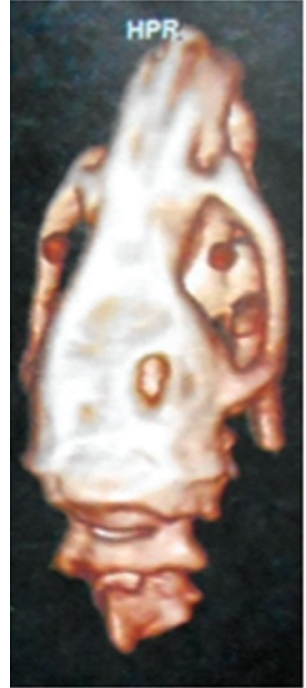

(A)

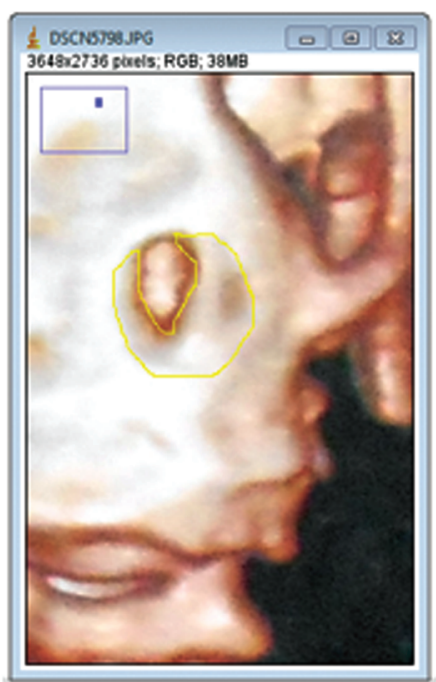

(B)

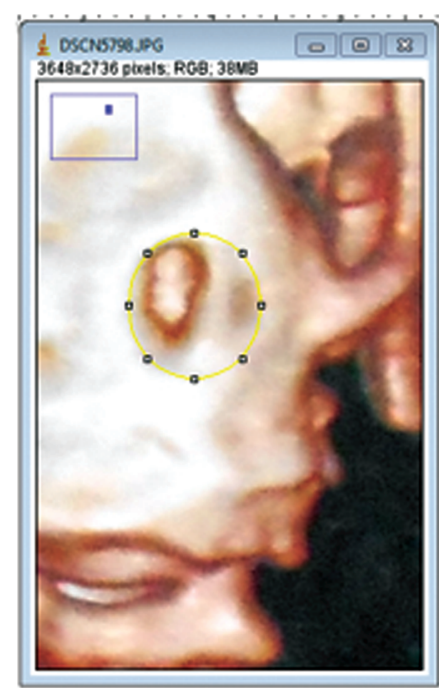

(C)

Fig. (6): A- 3D CT scan for group IV. B- The surface area marking of the newly formed bone by ImageJ $1.47 \mathrm{v}$. C- The surface area marking of the defect by ImageJ $1.47 \mathrm{v}$.

\section{RESULTS}

The rat's survival at all studied groups (Model 2) was uneventful apart from Four mortalities during surgical creation of the critical size defects ( 1 in group I, 1 in group II and 2 in group IV). Theses rats were replaced.

\section{Statistical methods:}

The collected data were coded, tabulated, and statistically analyzed using IBM SPSS statistics (Statistical Package for Social Sciences) software version 22.0, IBM Corp., Chicago, USA, 2013.

Descriptive statistics were done for quantitative data as minimum \& maximum of the range as well as means (standard deviation) for quantitative normally distributed data, while it was done for qualitative data as number and percentage.
Inferential analyses were done for quantitative variables using independent $t$-test in cases of two independent groups with normally distributed data. In qualitative data, inferential analyses for independent variables were done using Fisher's Exact test for differences between proportions with small expected numbers. The level of significance was taken at $p$-value $<0.050$ is significant, otherwise is non-significant.

\section{A- Gross evaluation at autopsy:}

Gross evaluation score was highest in group III $(10.5 / 11)$, followed by Group II (10/11), then group IV (9.3/11) and least in group I (2.1/11). Group III was significantly higher than groups I\& VI (Table 2) (Fig. 7). 
Table (2): Comparison between study groups using a gross evaluation score. Group III is significantly higher.

\begin{tabular}{lcccc}
\hline Findings & Group-I & Group-II & Group-III & Group-IV \\
\hline Mean \pm SD & $5.1 \pm 0.8$ & $10.0 \pm 0.8$ & $10.5 \pm 0.8$ & $9.3 \pm 1.2$ \\
Range & $4.0-6.0$ & $9.0-11.0$ & $9.0-11.0$ & $8.0-11.0$ \\
\hline
\end{tabular}

Comparison between group-III and other groups

\begin{tabular}{lllc}
\hline & Group-I & Group-II & Group-IV \\
\hline$p$ & $<0.001^{*}$ & 0.207 & $0.023^{*}$
\end{tabular}

Difference:

$\begin{array}{llll}\text { Mean } \pm \text { SE } & 5.4 \pm 0.4 & 0.5 \pm 0.4 & 1.3 \pm 0.5 \\ 95 \% \text { CI } & 4.5-6.2 & -0.3-1.3 & 0.2-2.3\end{array}$

\#Independent $t$-test.

Difference: Group-III relative to other groups.

CI : Confidence interval.

SD: Standard Variation.

SE: Standard error.

\section{B- Radiological evaluation:}

a- Radiological Extent of bone healing:

High grades of bone formation were most frequent in group-III $(62.5 \%$ healing of $75-100 \%$ of the defect and $37.5 \%$ healing of $50-74 \%$ ), followed

Table (3): Comparison between study groups regarding radiological extent of bone healing. Group III is significantly higher.

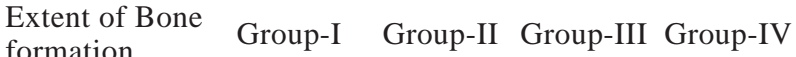

\begin{tabular}{lllll}
\hline $0-24 \%$ & $8(100.0 \%)$ & $7(87.5 \%)$ & $0(0.0 \%)$ & $0(0.0 \%)$ \\
$25-49 \%$ & $0(0.0 \%)$ & $1(12.5 \%)$ & $0(0.0 \%)$ & $5(62.5 \%)$ \\
$50-74 \%$ & $0(0.0 \%)$ & $0(0.0 \%)$ & $3(37.5 \%)$ & $3(37.5 \%)$ \\
$75-100 \%$ & $0(0.0 \%)$ & $0(0.0 \%)$ & $5(62.5 \%)$ & $0(0.0 \%)$ \\
\hline
\end{tabular}

Comparison between group-III and other groups

\begin{tabular}{lccc}
\hline & Group-I & Group-II & Group-IV \\
\hline$p$ & $<0.001^{*}$ & $<0.001 *$ & $<0.006^{*}$ \\
RR $(95 \% \mathrm{CI})$ & - & - & - \\
\hline
\end{tabular}

\#Fisher's Exact test.

RR: Relative rate (group-III relative to other groups regarding 75$100 \%$ ).

CI: Confidence interval

\section{b- Radiological bridging:}

High grades of radiological bridging the defect length with new bone were most frequent in group-III ( $75 \%$ entire length bridging and $25 \%$ partial length bridging), followed by groupIV $(37.5 \%$ partial length bridging and $62.5 \%$

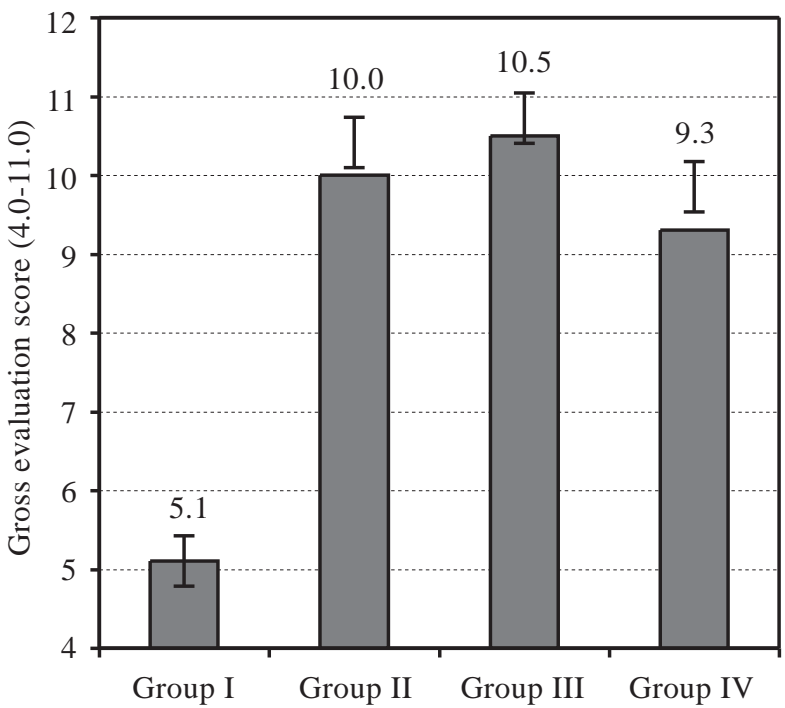

Fig. (7): Comparison between study groups using a gross evaluation score.

by group-IV $(62.5 \%$ healing of $25-49 \%$ of the defect and $37.5 \%$ healing of $50-74 \%$ of the defect), then group-II (12.5\% healing of $25-49 \%$ of the defect) and least in group-I (no healing). Difference were significant with all groups (Table 3) (Fig. 8).

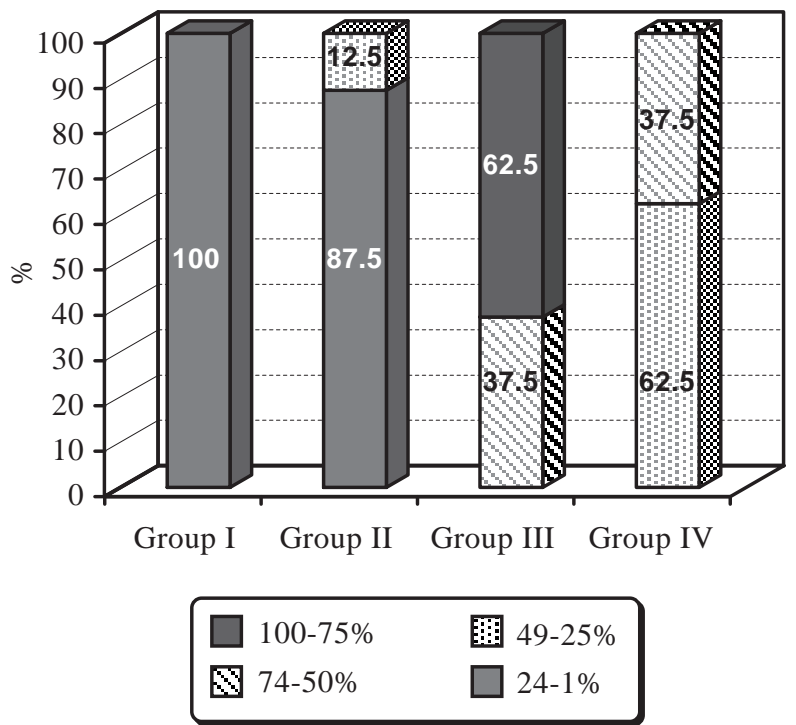

Fig. (8): Comparison between study groups regarding radiological extent of bone healing.

just formed bone over defect boarders), then group-II (100\% just formed bone over defect boarders), and least in group-I (50\% no healing and $50 \%$ just formed bone over defect boarders). Difference were significant with all groups (Table 4) (Fig. 9). 
Table (4): Comparison between study groups regarding radiological bridging. Group III is significantly higher.

\begin{tabular}{lllll}
\hline Bridging & Group-I & Group-II & Group-III & Group-IV \\
\hline $\begin{array}{c}\text { No bone } \\
\text { formation }\end{array}$ & $4(50.0 \%)$ & $0(0.0 \%)$ & $0(0.0 \%)$ & $0(0.0 \%)$ \\
$\begin{array}{c}\text { Just formed } \\
\text { over defect }\end{array}$ & $4(50.0 \%)$ & $8(100.0 \%)$ & $0(0.0 \%)$ & $5(62.5 \%)$ \\
$\begin{array}{c}\text { borders } \\
\text { Partial length } \\
\text { bridging }\end{array}$ & $0(0.0 \%)$ & $0(0.0 \%)$ & $2(25.0 \%)$ & $3(37.5 \%)$ \\
$\begin{array}{c}\text { Entire length } \\
\text { bridging }\end{array}$ & $0(0.0 \%)$ & $0(0.0 \%)$ & $6(75.0 \%)$ & $0(0.0 \%)$ \\
\hline
\end{tabular}

\begin{tabular}{llll}
\hline \multicolumn{3}{c}{ Comparison between group-III and different group } \\
\hline & Group-I & Group-II & Group-IV \\
\hline$p$ & $<0.001^{*}$ & $<0.001^{*}$ & $<0.003^{*}$ \\
& 5.000 & 5.000 & 5.000 \\
RR & $(1.448-17.271)$ & $(1.448-17.271)$ & $(1.448-17.271)$ \\
$(95 \%$ CI $)$ & & & \\
\hline
\end{tabular}

\#Fisher's Exact test. $\quad$ CI : Confidence interval.

RR: Relative rate (group-III relative to other groups regarding).

\section{C- Histological evaluation:}

The new bone formation was evident in groupIII, where multiple Islands of new irregular bone formation over dead necrotic bone that suggest the presence of the DBM remnants. The bone cells are seen inside their lacuanae resting over dead bone with small amount of Fibrous Tissue. In group-IV, a homogenous wide spaces resembling prolene mesh was seen and surrounded by fibrous tissue and newly formed bone. The amount of bone is more than fibrous tissue. In group-II, 3 zones could be identified; first zone is Dead bone with necrotic bone lamellae and absent cells which is sugessting

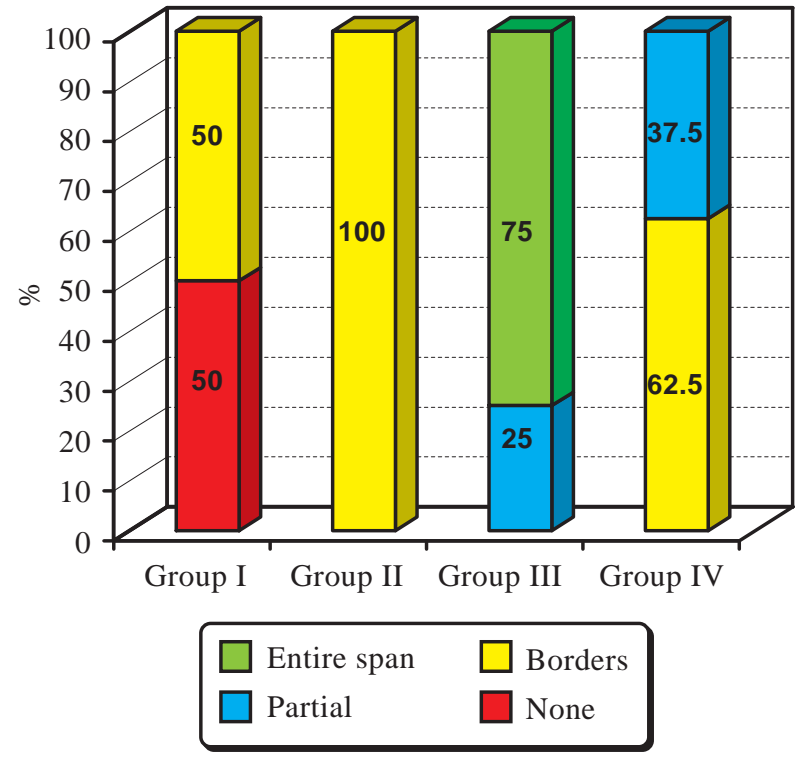

Fig. (9): Comparison between study groups regarding radiological bridging.

the prescence of DBM; second zone is junctional zone that shows a new bone formation where blood vessels and osteocytes are seen inside their lacuanae; third zone is the surrounding rim of the calverial bone. The control group (group-1), showed minimal islands of bone formation with greater amount dense fibrous tissue (Fig. 10). Interestingly, there were no abnormal cellular infiltration or immune reaction rather than normal cells included in normal healing process. This result is comparable to the result reached by Khaled, 2008 [28] and is considered another prove for the non-immunogenicity of the allogenic ADSC and for DBM.

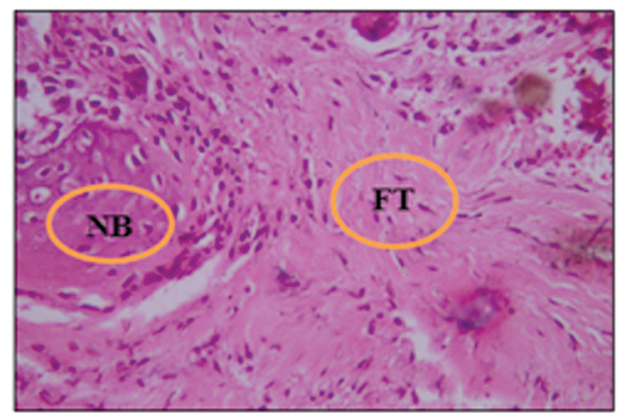

(A)

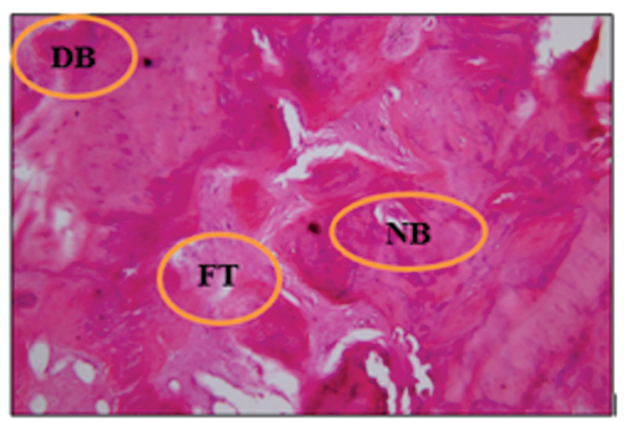

(C)

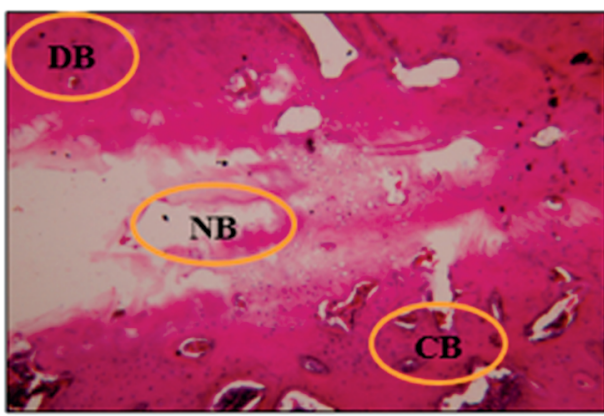

(B)

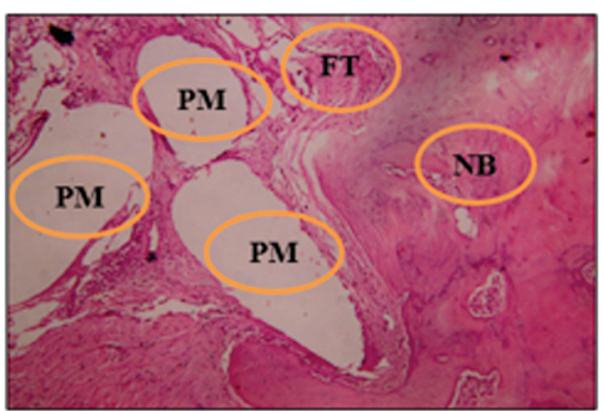

(D)
Fig. (10): Histological evaluation (H\&E x 400). A- Group I; showing island of bone formation (NB) with osteocytes seen inside lacuanae surrounded by dense fibrous tissue (FT). B- Group II; 3 zones; Dead bone(DB) with necrotic bone lamellae and absent cells; second zone is junctional zone with a new bone formation; third zone is the surrounding rim of the calverial bone (CB). C- Group III; Islands of new irregular bone formation over dead necrotic bone. D- Group IV; Homogenous wide spaces resembling prolene mesh (PM) and surrounde by fibrous tissue and newly formed bone. 
Bone tissue healing was most frequent in groupIII $(62.5 \%)$, followed by group-IV $(25 \%)$, fibrous tissue healing was more evident in group-I (62.5\%) then in group-II (50\%). Difference were significant with groups I\& II (Table 5) (Fig. 11).

Table (5): Histological evaluation; Comparison between study groups regarding type of tissue healing. Type of tissue Group-I Group-II Group-III Group-IV
healing

Mostly fibrous $5(62.5 \%) 4(50.0 \%) \quad 0(0.0 \%) \quad 0(0.0 \%)$

fibrous $>$ bone $3(37.5 \%) 4(50.0 \%) 3(37.5 \%) 6(75.0 \%)$

bone $>$ fibrous $0(0.0 \%) \quad 0(0.0 \%) \quad 5(62.5 \%) 2(25.0 \%)$

\begin{tabular}{lccc}
\hline \multicolumn{4}{c}{ Comparison between group-III and other group } \\
\hline & Group-I & Group-II & Group-IV \\
\hline$p$ & $0.006^{*}$ & $0.007^{*}$ & 0.315 \\
& 3.667 & 3.667 & 2.333 \\
RR & $(1.397-9.624)$ & $(1.397-9.624)$ & $(0.662-8.219)$ \\
$(95 \%$ CI $)$ & & &
\end{tabular}

\#Fisher's Exact test. CI : Confidence interval.

RR: Relative rate (group-III relative to other groups regarding complete filling).

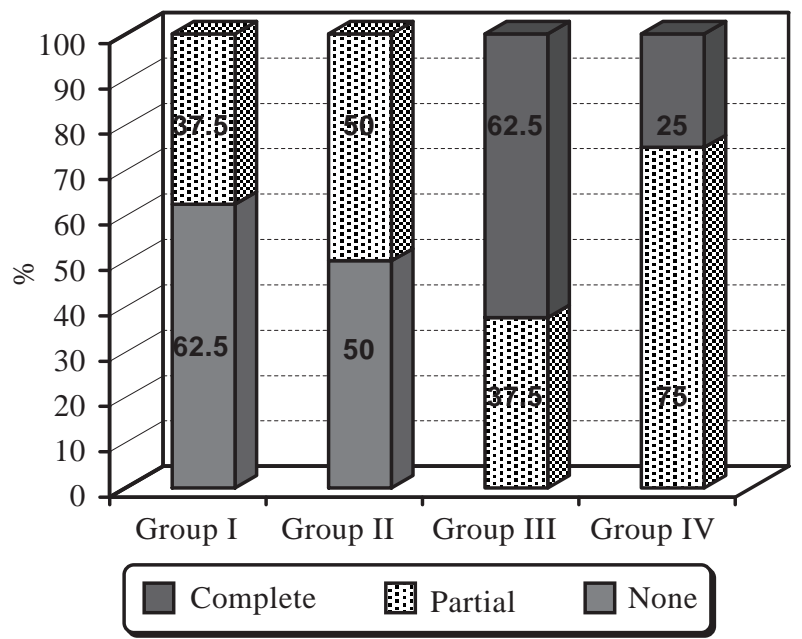

Fig. (11): Histological evaluation; Comparison between study groups regarding type of tissue healing.

\section{DISCUSSION}

The incidence of bone defects represents a major burden for the individual, families and the whole society. In USA, more than 1,600,000 bone grafts are implanted per year and $6 \%$ from this figure are craniofacial bone grafts [25]. Unfortunately, in our country, A statistical description for the magnitude of the critical size calvarial defects and the need for reconstruction is lacking.

Many reconstructive options are available from bone grafts, bone substitutes or bone transport methods [2]. The autograft is the golden standard, but, its main drawback is limited donor, extramorbidity and resorption [4].

Moreover, there is a high demand in reconstructive field for an already made bone that is available for urgent and extensive reconstruction where the needs are more than the autografts can meet. So, multiple studies were started to synthetize a novel tissue engineered bone and Researchers in this field tried to design a new bone tissue regenerate by seeding diverse types of stem cells on different scaffolds.

Though the lipoaspirate was considered as a waste for many years, it is a very rich source for ADSCS. This type of stem cells is clonogenic i.e. can form colonies in culture conditions [11,12]. Also, it has an osteogenic potential and surprisingly Its osteogenicity isn't greatly affected by age factor in contrast to BMSCs [13]. Furthermore, every processed $300 \mathrm{~mL}$ of lipoaspirate can produce between $1 \times 10^{7}$ and $6 \times 10^{8}$ ADSCs [14-17] and every $1 \mathrm{gm}$ of surgically excised adipose tissue, yield approximately $5 \times 10^{3}$ stem cells [18]. Its harvest and expansion are greatly easier than BMSCs [1920]. Also, ADSCs are more superior to BMSCs in bone regeneration as it could be maintained in vitro for longer periods with a constant doubling, more proliferative capacity and lower senescence $[11,12]$.

Despite the diversity of multiple scaffolding in the field of BTE, the DBM is considered an ideal scaffold. It is osteoconductive and non-immunogenic as the demineralization process exposes the proteins and other various growth factors, which are present in the extracellular matrix, to be available for the host environment and it destroys the antigenic surface structure of the bone [21]. The DBM is also osteoconductive [22]. It could be prepared and preserved easily. It is commercially available in various ranges of shapes and forms as such as morselized particles and struts.

In this study, the DBM scaffold is compared to prolene mesh scaffold which was used by Khaled, 2008 [28] and seeded by BMSCs. The advantages of this type of scaffolding are the availability, low cost, resistance to infection, malleability, biocompatibility and the ability for cell adherence and support. But its main disadvantages are the nondegradability; that might affect the mechanical property of the new tissue regenerate. Also, it is non osteoconductive nor osteogenic. On the other hand, the DBM scaffold biocompatible, biodegradable, non-immunogenic and at the same time, 
osteoconductive and to some extent osteogenic 26,27. So, seeding the DBM with ADSCs can cover nearly all phases of bone healing i.e. The osteogenesis, osteoconduction and osteoinduction.

The results obtained from this work advocates the use of Allogenic Demineralized Bone Matrix and Adipose Derived Stem Cells as a reconstructive tool for bone regeneration. But further clinical studies are needed to evaluate the rule of ADSCs seeded over DBM in the unfavorable conditions as this study and the previous studies were conducted in normal healthy conditions, but the clinical situation is a little bit different as many local factors as osteomyelitis, osteoradionecrosis and soft tissue scarring may exist or general factors like smoking, diabetes, obesity and osteoporosis may also affect healing. So, this work recommends Further clinical studies to produce an evidence based clinical application of bone tissue bioengineering in reconstruction of craniomaxillofacial bone defects.

\section{Conclusion:}

This study presents a beneficial method for reconstruction of critical size calvarial bone defects by preparing an already made non-immunogenic new bone by seeding DBM with ADSCs.

\section{REFERENCES}

1- Alejandro J., James A., Brian M., Michael T., Kelly W., Robert T. and Arnold S.: Repair of palatal bone defects using osteogenically differentiated fat-derived stem cells: Plast. Reconstr. Surg., 117 (3): 857-63, 2006.

2- Cancedda R., Paolo G. and Maddalena M.: Review, A tissue engineering approach to bone repair in large animal models and in clinical practice: Biomaterials, 28: 42404250, 2007.

3- Samartzis D., Shen F., Goldberg E. and An H.: Is autograft the gold standard in achieving radiographic fusion in one level anterior cervical discectomy and fusion with rigid anterior plate fixation?: Spine, 30 (15): 1756-61, 2005.

4- Pollock R., Alcelik I., Bhatia C., Chuter G., Lingutla K., Budithi C. and Krishna M.: Donor site morbidity following iliac crest bone harvesting for cervical fusion: A comparison between minimally invasive and open techniques.: Eur Spine. J., 17 (6): 845-52, 2008.

5- Habibovic P. and De Groot K.: Osteoinductive biomaterials properties and relevance in bone repair.: J. Tissue Eng. Regen. Med., 1 (1): 25-32, 2007.

6- Nandi S., Roy S., Mukherjee P., Kundu B., De D. and Basu D.: Orthopaedic applications of bone graft \& graft substitutes: A review. Indian J. Med. Res., 132 (1): 1530, 2010.

7- Marx R., Bone and bone graft healing.: Oral Maxillofac Surg. Clin. North. Am., 19: 455-66, 2007.

8- Murphy C. and O'Brien F.: Understanding the effect of mean pore size on cell activity in collagen-gly- cosaminoglycan scaffolds. Cell Adh Migr., 4 (3): $377-$ 381,2010

9- Liao H.T. and Chen C.T.: Osteogenic potential: Comparison between bone marrow and adipose-derived mesenchymal stem cells.: World Journal of Stem Cells.: 6 (3):288-295, 2014

10- Melek L.: Tissue engineering in oral and maxillofacial reconstruction.: Tanta Dental Journal, 12: 211-223, 2015.

11- Izadpanah R., Trygg C., Patel B., Kriedt C., Dufour J., Gimble J.M. and Bunnell B.A.: Biologic properties of mesenchymal stem cells derived from bone marrow and adipose tissue. J. Cell. Biochem., 99: 1285-1297, 2006.

12- Kern S., Eichler H., Stoeve J., Klüter H. and Bieback K.: Comparative analysis of mesenchymal stem cells from bone marrow, umbilical cord blood, or adipose tissue. Stem. Cells., 24: 1294-1301, 2006.

13- Chen H.T., Lee M.J., Chen C.H., Chuang S.C., Chang L.F., Ho M.L., Hung S.H., Fu Y.C., Wang Y.H., Wang H.I., et al.: Proliferation and differentiation potential of human adipose-derived mesenchymal stem cells isolated from elderly patients with osteoporotic fractures. J. Cell. Mol. Med., 16: 582-593, 2012.

14- Locke M., Windsor J. and Dunbar P.: Human adiposederived stem cells: Isolation, characterization and applications in surgery.: ANZ J. Surg., 79: 235-244, 2009.

15- Zuk P.A., Zhu M., Mizuno H., Huang J., Futrell J.W., Katz A.J., Benhaim P., Lorenz H.P. and Hedrick M.H.: Multilineage cells from human adipose tissue: Implications for cell- based therapies. Tissue. Eng., 7: 211-228, 2001.

16- Aust L., Devlin B., Foster S., Halvorsen Y.D., Hicok K., du Laney T., Sen A., Willingmyre G.D. and Gimble J.M.: Yield of human adipose derived adult stem cells from liposuction aspirates. Cytotherapy, 6: 7-14, 2004.

17- Mitchell J.B., McIntosh K., Zvonic S., Garrett S., Floyd Z.E., Kloster A., Di Halvorsen Y., Storms R.W., Goh B., Kilroy G., Wu X. and Gimble J.M.: Immunophenotype of human adipose-derived cells: Temporal changes in stromal-associated and stem cell-associated markers. Stem. Cells, 24: 376-85, 2006.

18- Mizuno H.: Adipose-derived Stem Cells for Tissue Repair and Regeneration: Ten Years of Research and a Literature Review. J. Nippon. Med. Sch., 76: 56-66, 2009.

19- Strem B.M., Hicok K.C., Zhu M., Wulur I., Alfonso Z., Schreiber R., Fraser J. and Hedrick M.: Multipotential differentiation of adipose tissue-derived stem cells. Keio. J. Med., 54: 132-141, 2005.

20- Tollemar V., Collier Z., Mohammed M., Lee M., Ameer G. and Reid R.: Stem cells, growth factors and scaffolds in craniofacial regenerative medicine., Genes \& Diseases, 3: 56-71, 2016.

21- Katz J., Nataraj C., Jaw R., Deigl E. and Bursac P.: Demineralized bone matrix as an osteoinductive biomaterial and in vitro predictors of its biological potential.: J. Biomed. Mater. Res. B Appl Biomater., 89 (1): 127 34, 2009.

22- Biswas D., Bible J., Whang P.G., Miller C.P, Jaw R., Miller S. and Grauer J.N.: Augmented Demineralized Bone Matrix: A Potential Alternative for Posterolateral Lumbar Spinal Fusion. Am J. Orthop., 39 (11): 531-538, 2010. 
23- Gebhart M. and Lane J.: A radiographical and biomechanical study of demineralized bone matrix implanted into a bone defect of rat femurs with and without bone marrow. Acta. Orthopedica Belgica., 57 (2): 130-43, 1991.

24- Lu F., Mizuno H., Uysal C., Cai X., Oqawa R. and Hyakusoku H.: Improved Viability of Random Pattern Skin Flaps through the Use of Adipose Derived Stem Cells.: Plast. Reconstr. Surg., 121 (1): 50-58, 2008.

25- Greenwald AS., Boden S.D., Goldberg V.M., Khan, Y., Laurencin C.T. and Rosier R.N.: American Academy of Orthopaedic Surgeons: The Committee on Biological Implants. Bone-graft substitutes: Facts, fictions, and applications. J. Bone Jt. Surg. Am., 83: 98-103, 2001.
26- Tynan J., Schachar N., Marshall G. and Gray R..: Pathologic fracture through a unicameral bone cyst of the pelvis: CT-guided percutaneous curettage, biopsy, and bone matrix injection. J. Vas.c Interv. Radiol., 16 (2): 293-296, 2005.

27- Docquier P. and Delloye C.: Treatment of aneurysmal bone cysts by introduction of Demineralized bone and Autogenous bone marrow. JBJS, 87 (10): 2253-2258, 2005 .

28- Khaled E.G.: A study of Evaluation of Cranial Bone Production Using Bone Marrow Stem Cells. M.D. thesis. Faculty of medicine, Ain Shams. University, Cairo, Egypt, 2008. 